Proceeding Paper

\title{
A One-Pot Synthesis of Fluoro $\alpha$-Acylamino Amide-Xanthates via an IMCR-Post Transformation Strategy ${ }^{\dagger}$
}

\author{
Manuel A. Rentería-Gómez 1, Tannya R. Ibarra-Rivera ${ }^{2}$ and Rocío Gámez-Montaño 1,* \\ 1 Departamento de Química, Universidad de Guanajuato, Noria Alta S/N, Col. Noria Alta, \\ 36050 Guanajuato, Mexico; vmxrntclonealex@gmail.com \\ 2 Departamento de Química Analítica, Universidad Autónoma de Nuevo León, Facultad de Medicina, Fco. I. \\ Madero s/n, Col. Mitras Centro, Monterrey, 64460 Nuevo León, Mexico; tannya.ibarrarv@unal.edu.mx \\ * Correspondence: rociogm@ugto.mx; Tel.: +52-473-73-20006 (ext. 8191) \\ + Presented at the 24th International Electronic Conference on Synthetic Organic Chemistry, \\ 15 November-15 December 2020; Available online: https:/ecsoc-24.sciforum.net/.
}

Citation: Rentería-Gómez, M.A.; Ibarra-Rivera, T.R.; GámezMontaño, R. A One-Pot Synthesis of Fluoro $\alpha$-Acylamino AmideXanthates via An IMCR-Post Transformation Strategy. Chem. Proc. 2021, 3, 59. https://doi.org/10.3390/ ecsoc-24-08421

Academic Editors: Julio A. Seijas and M. Pilar Vázquez-Tato

Published: 14 November 2020

Publisher's Note: MDPI stays neutral with regard to jurisdictional claims in published maps and institutional affiliations.

Copyright: $₫ 2020$ by the authors. Licensee MDPI, Basel, Switzerland. This article is an open access article distributed under the terms and conditions of the Creative Commons Attribution (CC BY) license (http://creativecommons.org/licenses/by/4.0/)

\begin{abstract}
A series of six novel amide-xanthate products containing several fluorine atoms were prepared in moderate to good yields (40-92\%) via an isocyanide-based multicomponent reaction (IMCR) of 5-CR by Ugi-4CR followed by an $\mathrm{S}_{\mathrm{N}} 2$ sequence in a one-pot manner. The design of molecules with fluorine atoms is of interest in medicinal chemistry and a research line of our interest. The role of fluorine atoms in biological properties is well documented, improving bioavailability, lipophilicity, and metabolic resistance in bioactive molecules.
\end{abstract}

Keywords: multicomponent reaction; amide-xanthates; heterocycle peptidomimetics; fluorine atoms

\section{Introduction}

Multicomponent reactions (MCRs) are defined as reactions in which three or more starting materials react to form a product where basically all or most of the atoms contribute to the newly formed product. MCRs have many advantages over traditional multistep sequential reactions [1]. Among the MCRs, the isocyanide-based multicomponent reactions (IMCRs) are most relevant for the synthesis of peptidomimetics. The Ugi fourcomponent reaction (Ugi-4CR) is probably one of the most utilized IMCRs during the last decade. This reaction allows the rapid preparation of $\alpha$-acylamino amides derivatives. Ugi-4CR products can exemplify a wide variety of substitution patterns and are precursors to the synthesis of peptidomimetics that have potential pharmaceutical applications [2].

The role of fluorine atoms in organic compounds to improve bioavailability, lipophilicity, and metabolic resistance in bioactive molecules is well documented [3]. Therefore, the synthesis of fluoro $\alpha$-acylamino amides as a synthetic platform can be an important alternative for the synthesis of heterocycles which is of interest in medicinal chemistry.

On the other hand, xanthate is an interesting functional group and has synthetic potential from radical chemistry [4]. Therefore, the one-pot incorporation of this functional group after an IMCR is an interesting strategy for the synthesis of privileged heterocyclic peptidomimetics (PHPs) via post-MCR transformation. Examples of these are azaspirodienones (1), oxindoles (2), tetrazol-azepinoindolones (3) (Figure 1) [5-7]. 
<smiles>[R4]NC(=O)C([R])N1CC2(C=CC(=O)C([R])=C2[R])CC1=O</smiles>

$\mathrm{R}^{1}=\mathrm{Et}, i-\mathrm{Pr}, 4-\mathrm{CIPh}$,

$\mathrm{R}^{2}=\mathrm{H}$, OMe

$\mathrm{R}^{3}=\mathrm{H}, \mathrm{OMe}$

$\mathrm{R}^{4}=$ tert-Bu, c-Hex 2,6-diMePh<smiles>[R]NC(=O)C([R])N1Cc2cc(OC)ccc2C1=O</smiles>

$\mathrm{R}^{1}=\mathrm{Ph}, 4-\mathrm{CIPh}$, tert-Bu, $i-\mathrm{Pr}$

$\mathrm{R}^{2}=$ tert-Bu, $\mathrm{c}-\mathrm{Hex}$ 2,6-diMePh

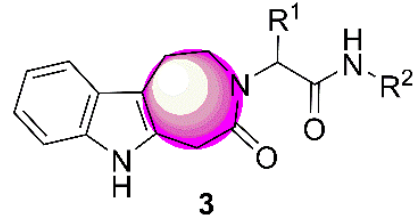

$\mathrm{R}^{1}=\mathrm{Ph}, 4-\mathrm{ClPh}, 4-\mathrm{BrPh}, 2,3-\mathrm{diMePh}$,

piperonyl, c-Hex, 4-diMe-NPh

$\mathrm{R}^{2}=$ tert-Bu, $c-\mathrm{Hex}$ 2,6-diMePh

Figure 1. Some privileged heterocyclic peptidomimetics (PHPs) synthesized via post-multicomponent reactions (MCR) Table 2. and alkyl halides with a strong base as hydroxide, which is particularly problematic as it is also a substantial nucleophile, capable of hydrolyzing numerous functionalities, and it is generally restricted to alkyl substituents (see Scheme 1) [8]. The most effective methodologies for the synthesis of complex xanthates are using an IMCR followed by SN2 with potassium ethyl xanthogenate salt (see Scheme 1) [5-7,9].

The methodology described here allows us to perform the one-pot synthesis via Ugi$4 \mathrm{CR}$ coupled $\mathrm{S}_{\mathrm{N}} 2$ strategy of fluoro $\alpha$-acylamino amide-xanthates (10a-f). These complex xanthate products are important precursors for the synthesis of PHP products (Scheme 1).
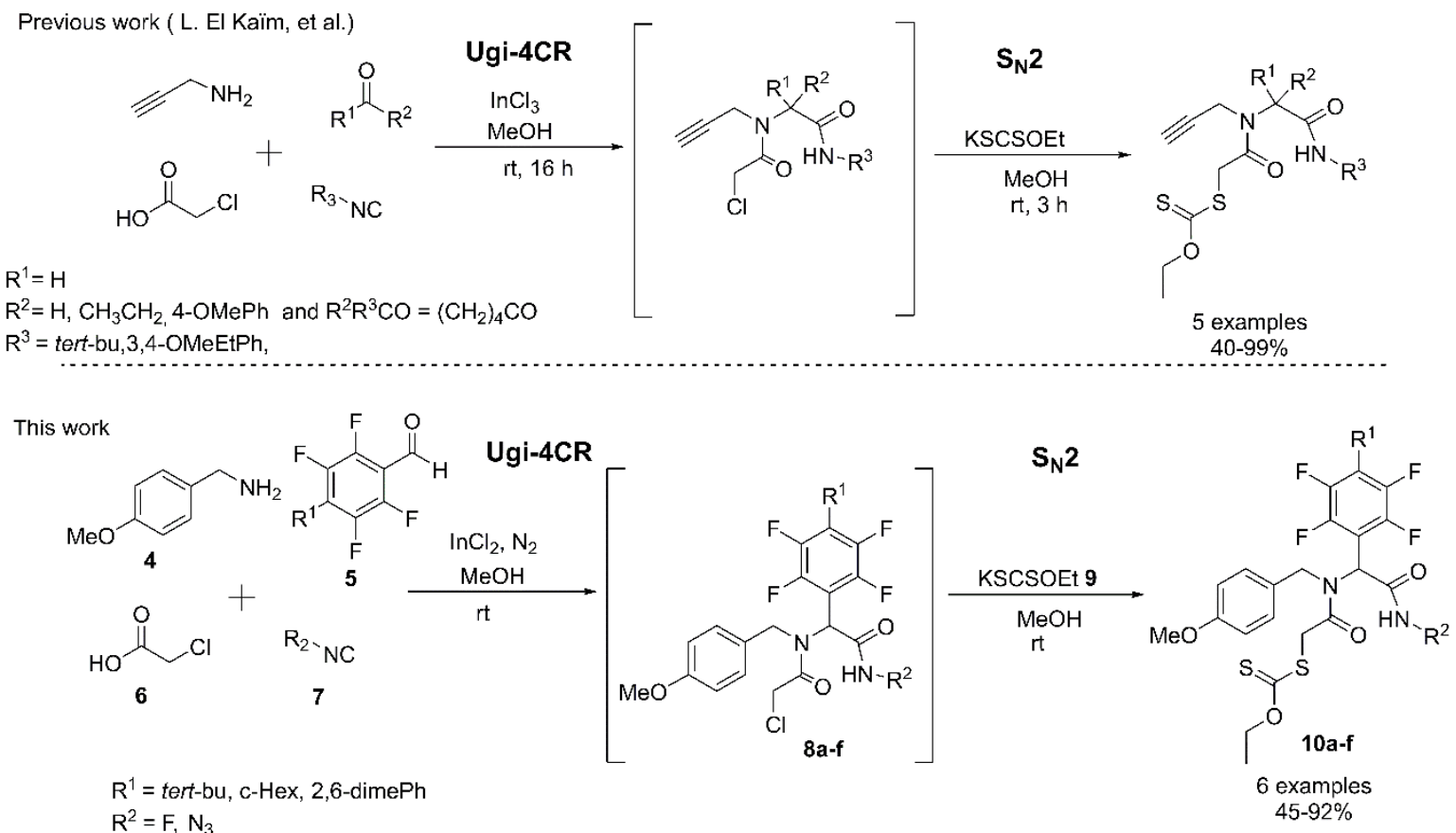

Scheme 1. Previous works and this work.

\section{Results and Discussion}

In order to develop conditions for the synthesis of $\alpha$-acylamino amide-xanthates, we started the optimization for the synthesis of the $\alpha$-acylamino amide analogue $8 \mathrm{~d}$ by reacting 4-methoxybenzylamine (4), 4-azido-2,3,5,6-tetrafluorobenzaldehyde (5), chloroacetic acid (6), and tert-butyl isocyanide (7) in methanol anhydrous. Initially, we performed the Ugi-4CR at room temperature, in the absence of a catalyst, the $8 \mathrm{~d}$ product was generated in $72 \%$ after 7 days (Entry 1, Table 1). The success of the Ugi-4CR lies in the formation of the imine, which was favored by Lewis acids. When $10 \mathrm{~mol} \% \mathrm{InCl}_{3}$ was employed as catalyst, the $8 \mathrm{~d}$ was obtained with a yield of $35 \%$ after a reaction time of $3 \mathrm{~h}$ (Entry 2). The yield was increased when the reaction was performed during $24 \mathrm{~h}$. Then, a yield of $66 \%$ 
was obtained. (Entry 3). The use of microwave (MW) did not lead to the desired product and the reaction did not show a significant progress after one hour at $50{ }^{\circ} \mathrm{C}$ (Entry 4 ). The best reaction conditions were obtained for $20 \% \mathrm{~mol}$ of $\mathrm{InCl} 3$ and 1.4 equiv. carboxylic acid, after $24 \mathrm{~h}$ of reaction at room temperature (Entry 5).

Table 1. Reaction optimizing conditions 8d.

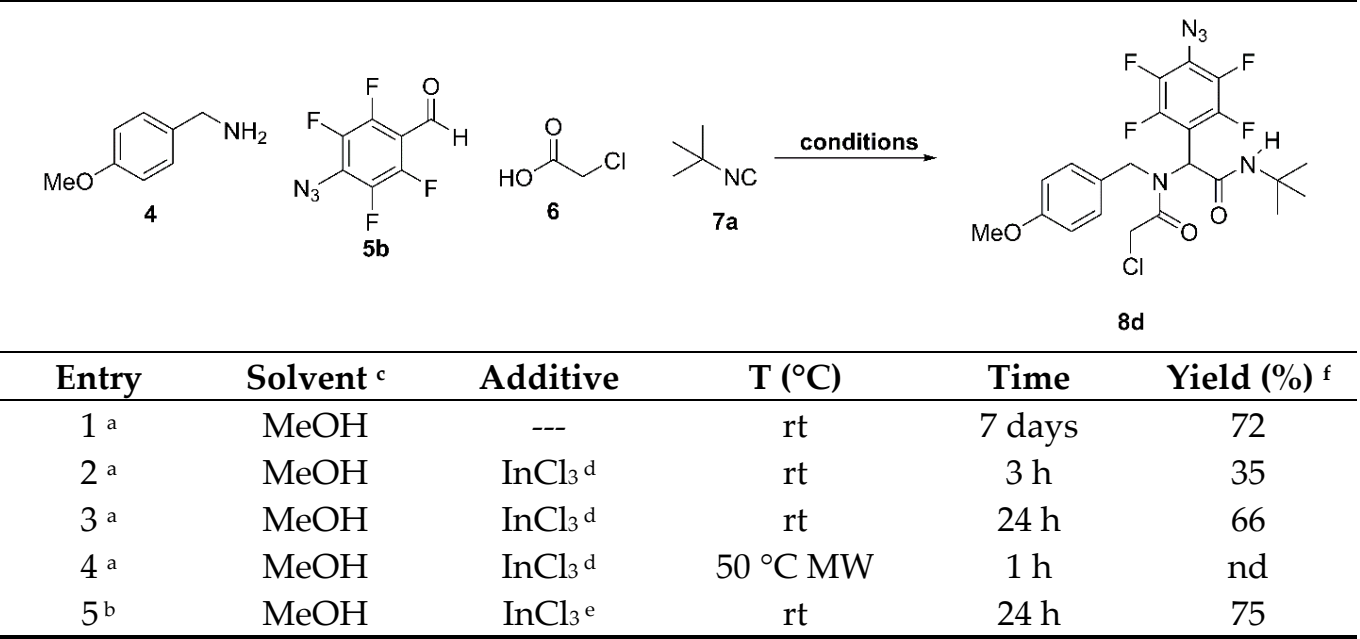

a Reactions performed with 1.0 equiv. 4-methoxybenzylamine (4), 1.0 equiv. of 4-azido-2,3,5,6tetrafluorobenzaldehyde (5b), 1.0 equiv. of chloroacetic acid (6) and 1.0 equiv. of tert-butyl isocyanide (7a). ${ }^{\mathrm{b}}$ Reactions performed with 1.4 equiv. of 4-methoxybenzylamine (4), 1.0 equiv. of 4 -azido-2,3,5,6-tetrafluorobenzaldehyde (5b), 1.4 equiv. of chloroacetic acid (6) and 1.0 equiv. of tertbutyl isocyanide (7a). ${ }^{\mathrm{c}}[1.0 \mathrm{M}]$ anhydrous ${ }^{\mathrm{d}} 10 \% \mathrm{~mol}$. ${ }^{\mathrm{e}} 20 \% \mathrm{~mol}{ }^{\mathrm{f}}$ Isolated yield. $\mathrm{rt}=$ room temperature. nd $=$ not determined .

Once the synthesis of the Ugi-4CR products was optimized, the one-pot synthesis of the $\alpha$-acylamino amide-xanthates was carried out through an $S_{N} 2$-type reaction when adding the potassium salt of xanthic acid to form the Ugi-product xanthate $10 \mathrm{~d}$. The versatility of the developed methodology was examined using different aldehydes, such as 4-azido2,3,5,6-tetrafluorobenzaldehyde (5a) and 2,3,4,5,6-pentafluorobenzaldehyde (5b), isocyanides as tert-butyl, cyclohexyl, and 2,6-dimethylphenyl (7a-c). The respective amide-xanthate products $10 \mathrm{a}-\mathrm{f}$ were obtained in moderate to good yields (40-92\%) (Scheme 2).

Figures 2 and 3 shows the ${ }^{1} \mathrm{H}$ and ${ }^{13} \mathrm{C}$ NMR spectra of the fluoro $\alpha$-acylamino amidexanthate $10 \mathrm{a}$. 
<smiles>COc1ccc(CN)cc1</smiles><smiles>O=C(O)CCl</smiles><smiles>[R]c1c(F)c(F)c(C=O)c(F)c1F</smiles>
5a-b $\mathrm{R}_{2}-\mathrm{NC}$

7a-c

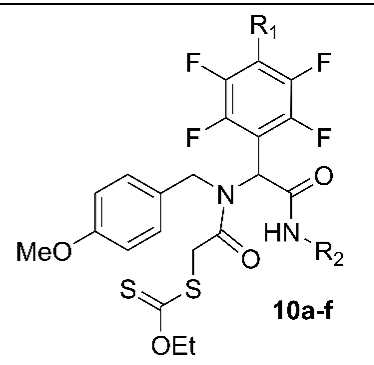

KS $\stackrel{\mathrm{S}}{\mathrm{S}} \frac{\mathrm{InCl}_{3}, \mathrm{~N}_{2}}{\mathrm{MeOH}}$ 24-28 h<smiles>CCOC(=S)SCC(=O)N(Cc1ccc(OC)cc1)C(C(=O)NC(C)(C)C)c1c(F)c(F)c(F)c(F)c1F</smiles>

10a $85 \%$<smiles>CCOC(=S)SCC(=O)N(Cc1ccc(OC)cc1)C(C(=O)NC(C)(C)C)c1c(F)c(F)c(N)c(F)c1F</smiles>

10d $67 \%$<smiles>CCOC(=S)SCC(=O)N(Cc1ccc(OC)cc1)C(C(=O)NC1CCCCC1)c1c(F)c(F)c(F)c(F)c1F</smiles>

10b $75 \%$<smiles>CCOC(=S)SCC(=O)N(Cc1ccc(OC)cc1)C(C(=O)NC1CCCCC1)c1c(F)c(N)c(N)c(F)c1F</smiles>

$10 \mathrm{e} 92 \%$<smiles>CCOC(=S)SCC(=O)N(Cc1ccc(OC)cc1)C(C(=O)Nc1c(C)cccc1C)c1c(F)c(F)c(F)c(F)c1F</smiles>

10c $45 \%$<smiles>CCOC(=S)SCC(=O)N(Cc1ccc(OC)cc1)C(C(=O)Nc1c(C)cccc1C)c1c(F)c(N)c(N)c(F)c1F</smiles>

$10 f 55 \%$

Scheme 2. Substrate scope. 


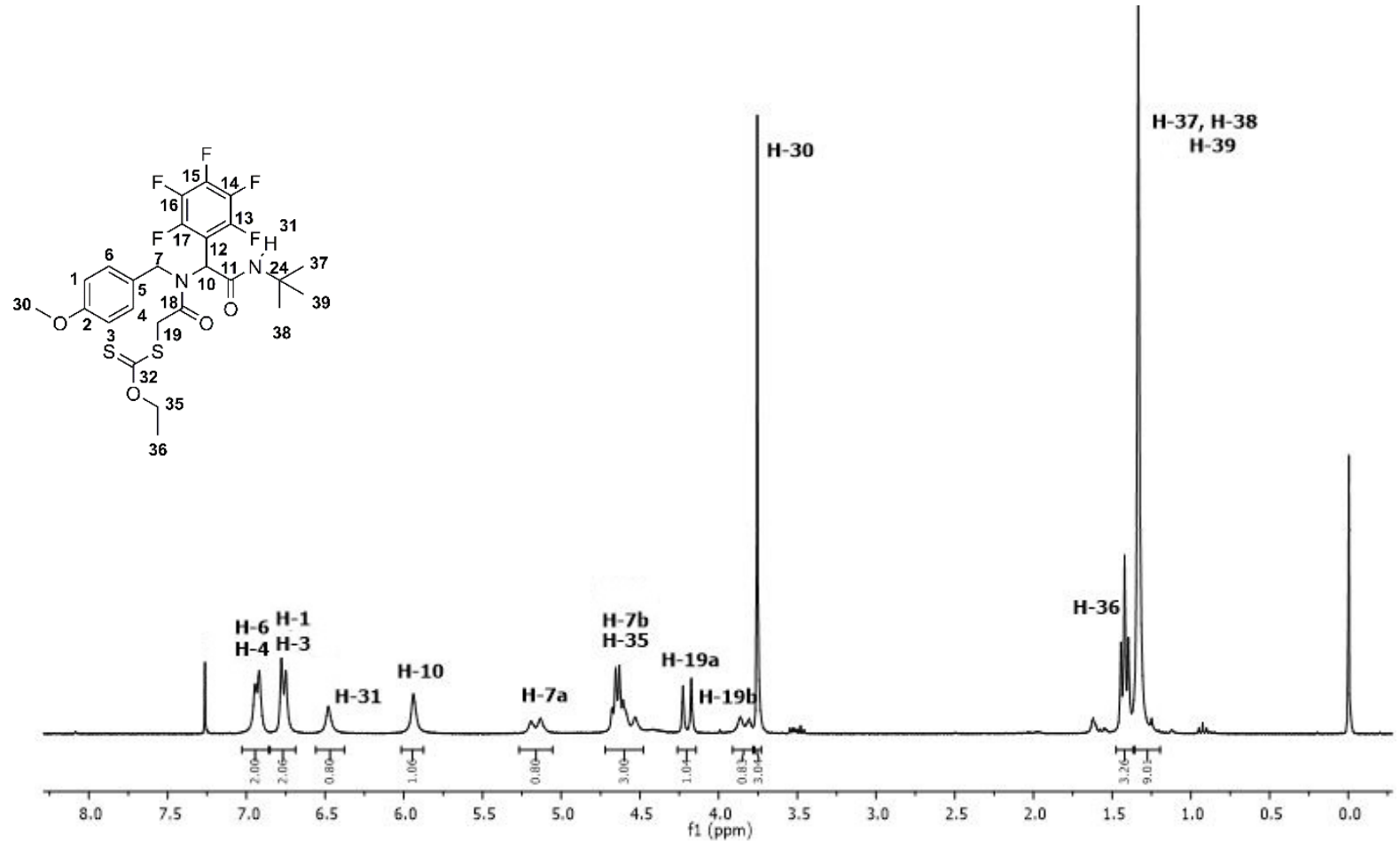

Figure 2. ${ }^{1} \mathrm{H}$ NMR spectrum of fluoro $\alpha$-acylamino amide-xanthate $10 \mathrm{a}$.
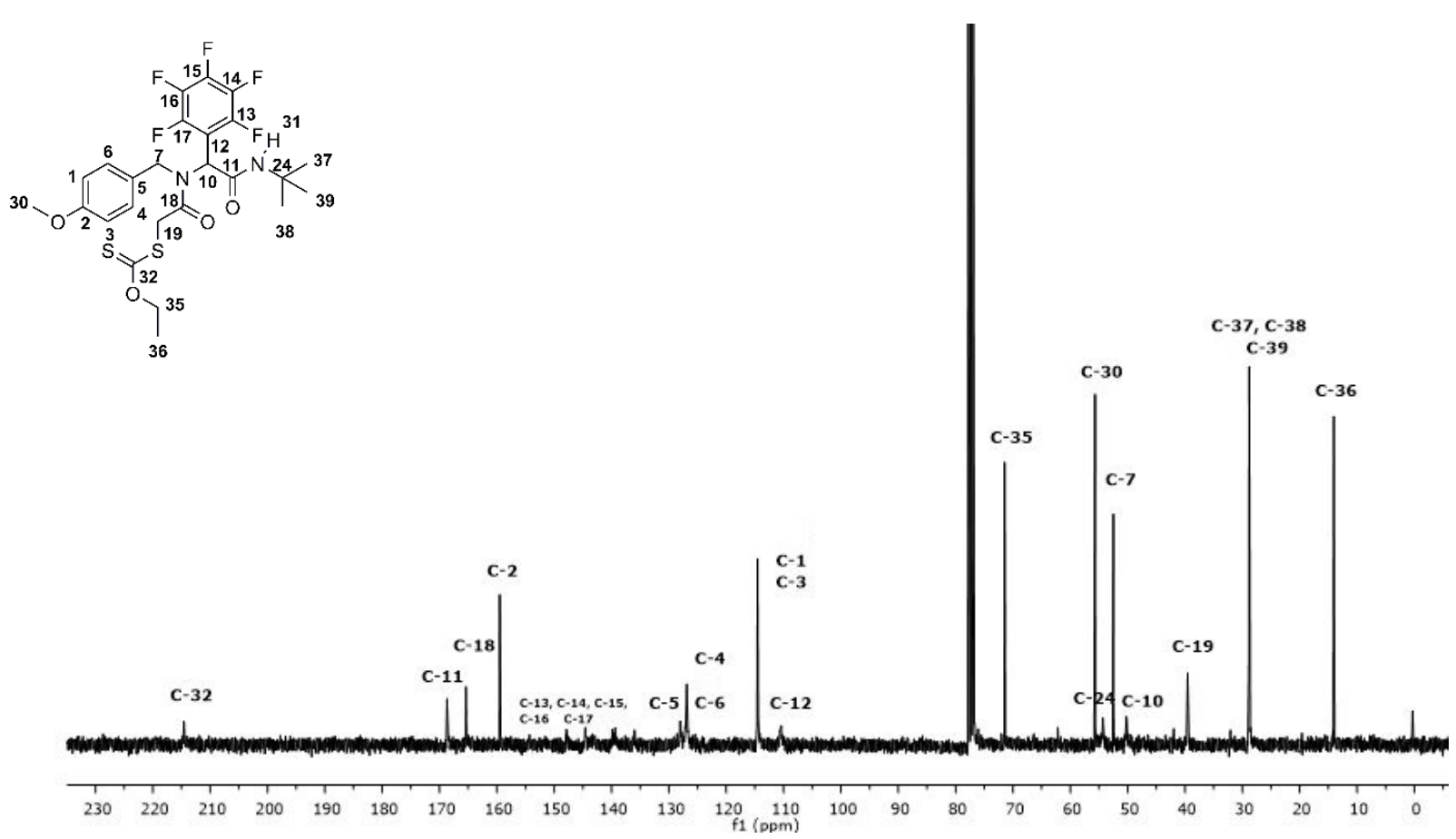

Figure 3. ${ }^{13} \mathrm{C}$ NMR spectrum of fluoro $\alpha$-acylamino amide-xanthate 10a.

\section{Experimental Section}

\subsection{General Information, Instrumentation, and Chemicals}

${ }^{1} \mathrm{H}$ and ${ }^{13} \mathrm{C}$ NMR spectra were acquired on Varian Gemini spectrometers $(200 \mathrm{MHz})$ and Varian Unity $(300 \mathrm{MHz})$. The solvent used was deuterated chloroform $\left(\mathrm{CDCl}_{3}\right)$. Chemical shifts are reported in parts per million $(\delta / p p m)$. The internal reference for ${ }^{1} \mathrm{H}$ NMR spectra is trimethylsilane at $0.0 \mathrm{ppm}$. The internal reference for ${ }^{13} \mathrm{C}$ NMR spectra is $\mathrm{CDCl}_{3}$ at $77.0 \mathrm{ppm}$. Coupling constants are reported in Hertz $(\mathrm{J} / \mathrm{Hz})$. Multiplicities of the 
signals are reported using the standard abbreviations: singlet (s), doublet (d), triplet (t), quartet (q), and multiplet (m). NMR spectra were analyzed using the MestreNova software version 10.0.1-14719. IR spectra were acquired on a Perkin Elmer 100 spectrometer using an Attenuated Total Reflectance (ATR) method with neat compounds. The absorbance peaks are reported in reciprocal centimeters $\left(v_{\max } / \mathrm{cm}^{-1}\right)$. Reaction progress was monitored by Thin-Layer Chromatography (TLC) on precoated silica-gel $60 \mathrm{~F}_{254}$ plates and the spots were visualized under UV light at 254 or $365 \mathrm{~nm}$. Mixtures of hexane with ethyl acetate (EtOAc) were used to run TLC and for measuring the retention factors $\left(R_{f}\right)$. Flash column chromatography was performed using silica gel (230-400 mesh) and mixtures of hexane with EtOAc in different proportions $(v / v)$ were used as the mobile phase. All reagents were purchased from Sigma-Aldrich and were used without further purification. Chemical names and drawings were obtained using the ChemBioDraw Ultra 13.0.2.3020 software package. The purity for all the synthesized products (up to 99\%) was assessed by NMR.

\subsection{Synthesis and Characterization of the Fluoro $\alpha$-Acylamino Amide-Xanthates 10a-f}

General procedure 1 (GP1): In a round-bottomed flask equipped with a magnetic stirring bar, 4-Methoxybenzylamine (1.4 equiv.) and $\mathrm{InCl} 3(10 \% \mathrm{~mol})$ were added to a $0.3 \mathrm{M}$ solution of p-methoxyaniline (1.0 equiv.) in anhydrous $\mathrm{MeOH}$ under nitrogen atmosphere at room temperature. After $60 \mathrm{~min}$, chloroacetic acid (1.4 equiv.) and $\mathrm{InCl}_{3}(10 \% \mathrm{~mol})$ were added. Later, tert-butyl isocyanide (1.0 equiv.) was added. The reaction mixture was stirred for $21-25 \mathrm{~h}$ at room temperature and then, the potassium ethyl xanthogenate salt (1.5 equiv.) was added. The reaction mixture was stirred for $3 \mathrm{~h}$ at room temperature. The solvent was removed until dryness. The crude was diluted in excess of AcOEt and washed with brine. The combined organic layer was dried over anhydrous $\mathrm{Na}_{2} \mathrm{SO}_{4}$. The solvent was removed until dryness. The crude was purified by silica-gel column chromatography to obtain the products $10 \mathrm{a}-\mathrm{f}$.

3.2.1. S-(2-((2-(tert-Butylamino)-2-oxo-1-(perfluorophenyl)ethyl)(4-methoxybenzyl)amino)-2-oxoethyl) O-ethyl carbonodithioate (10a)

The product was obtained in $85 \%$ as a white solid after purification by silica-gel column chromatography using a mixture of ethyl acetate with hexanes $(15-20 \% \mathrm{v} / \mathrm{v})$ as eluent $R_{f}=0.43$ (hexanes-AcOEt, 8/2, v/v); $\mathrm{mp}=130-134{ }^{\circ} \mathrm{C}$, FT-IR (ATR) $v_{\max } / \mathrm{cm}^{-1} 1696,1646$ ( $\mathrm{C}=\mathrm{O}$ amide), 3276 (NH amide); ${ }^{1} \mathrm{H}$ NMR (300 MHz, $\left.\mathrm{CDCl}_{3}, \mathrm{TMS}\right): \delta 6.93$ (d, J = $9.0 \mathrm{~Hz}$, $2 \mathrm{H}), 6.76(\mathrm{~d}, J=9.0 \mathrm{~Hz}, 2 \mathrm{H}), 6.48(\mathrm{~s}, 1 \mathrm{H}), 5.94(\mathrm{~s}, 1 \mathrm{H}), 5.16(\mathrm{~d}, J=18.0,1 \mathrm{H}), 4.68-4.53(\mathrm{~m}$, $3 \mathrm{H}), 4.20(\mathrm{~d}, J=18.0 \mathrm{~Hz}, 1 \mathrm{H}), 3.83(\mathrm{~d}, J=18.0 \mathrm{~Hz}, 1 \mathrm{H}), 3.75(\mathrm{~s}, 3 \mathrm{H}), 1.42(\mathrm{t}, \mathrm{J}=6.0 \mathrm{~Hz}, 3 \mathrm{H})$, 1.33 (s, H, 9H); ${ }^{13} \mathrm{C}$ NMR (75 MHz, CDCl 3 , TMS): $\delta$ 214.6, 168.7, 165.4, 159.5, 147.9, 144.5, $139.9,139.4,136.0,128.0,126.9,114.5,110.4,71.5,55.7,54.3,52.5,50.2,39.5,28.8,14.0$.

3.2.2. S-(2-((2-(Cyclohexylamino)-2-oxo-1-(perfluorophenyl)ethyl)(4-methoxybenzyl)amino)-2-oxoethyl) O-ethyl carbonodithioate (10b)

The product was obtained in $75 \%$ as a white solid after purification by silica-gel column chromatography using a mixture of ethyl acetate with hexanes $(15-20 \% v / v)$ as eluent $R_{f}=0.38$ (hexanes-AcOEt, 8/2, v/v); $\mathrm{mp}=148-152{ }^{\circ} \mathrm{C}$, FT-IR (ATR) $v_{\max } / \mathrm{cm}^{-1} 1654,1614$ (C=O amide) 3345 (NH amide); ${ }^{1} \mathrm{H}$ NMR (200 MHz, $\left.\mathrm{CDCl}_{3}, \mathrm{TMS}\right): \delta 6.93$ (d, $J=10.0 \mathrm{~Hz}$, $2 \mathrm{H}), 6.76(\mathrm{~d}, J=8.0 \mathrm{~Hz}, 2 \mathrm{H}), 6.55(\mathrm{~s}, 1 \mathrm{H}), 6.26(\mathrm{~d}, J=8.0,1 \mathrm{H}), 5.20(\mathrm{~d}, J=18.0,1 \mathrm{H}), 4.70-4.50$ $(\mathrm{m}, 3 \mathrm{H}), 4.21(\mathrm{~d}, J=16.0 \mathrm{~Hz}, 1 \mathrm{H}), 3.84-3.75(\mathrm{~m}, 5 \mathrm{H}), 2.00-1.00(\mathrm{~m}, 13 \mathrm{H}) ;{ }^{13} \mathrm{C}$ NMR $(50 \mathrm{MHz}$, $\left.\mathrm{CDCl}_{3}, \mathrm{TMS}\right): \delta 215.3,168.7,165.4,159.4,148.6,143.7,140.2,139.0,135.1,127.8,126.8,114.5$, $110.3,71.6,55.6,53.8,50.2,49.4,39.3,33.0,25,7,25.2,14.0$.

3.2.3. S-(2-((2-((2,6-Dimethylphenyl)amino)-2-oxo-1-(perfluorophenyl)ethyl)(4-methoxybenzyl)amino)-2-oxoethyl) O-ethyl carbonodithioate (10c) 
The product was obtained in $40 \%$ as a white solid after purification by silica-gel column chromatography using a mixture of ethyl acetate with hexanes (15-20\% v/v) as eluent $R_{f}=0.28$ (hexanes-AcOEt, 8/2, v/v); $\mathrm{mp}=166-170{ }^{\circ} \mathrm{C}, \mathrm{FT}-\mathrm{IR}(\mathrm{ATR}) \mathrm{v}_{\max } / \mathrm{cm}^{-1} 1663,1613$ (C=O amide), 3251 (NH amide); ${ }^{1} \mathrm{H}$ NMR (300 MHz, $\left.\mathrm{CDCl}_{3}, \mathrm{TMS}\right): \delta 7.71$ (s, 1H), 7.15-7.05 $(\mathrm{m}, 3 \mathrm{H}), 6.94(\mathrm{~d}, J=9.0 \mathrm{~Hz}, 2 \mathrm{H})), 6.88(\mathrm{~s}, 1 \mathrm{H}), 6.78(\mathrm{~d}, J=9.0 \mathrm{~Hz}, 2 \mathrm{H}), 5.37(\mathrm{~d}, J=18.0,1 \mathrm{H})$, $4.70-4.53(\mathrm{~m}, 3 \mathrm{H}), 4.29(\mathrm{~d}, J=18.0 \mathrm{~Hz}, 1 \mathrm{H}), 3.87-3.62(\mathrm{~m}, 4 \mathrm{H}), 2.22(\mathrm{~s}, 6 \mathrm{H}), 1.38(\mathrm{t}, \mathrm{J}=6.0$ $\mathrm{Hz}, 3 \mathrm{H}), 1.33$ (s, H, 3H); ${ }^{13} \mathrm{C}$ NMR $\left(75 \mathrm{MHz}, \mathrm{CDCl}_{3}, \mathrm{TMS}\right): \delta 216.0,169.2,165.4,165.1,159.6$, 136.0, 133.2, 128.6, 128.0, 127.7, 126.7, 114.7, 109.8, 71.8, 55.8, 53.7, 50.1, 39.2, 18.7, 14.0.

3.2.4. S-(2-((1-(4-Azido-2,3,5,6-tetrafluorophenyl)-2-(tert-butylamino)-2-oxoethyl)(4methoxybenzyl)amino)-2-oxoethyl) O-ethyl carbonodithioate (10d)

The product was obtained in $67 \%$ as a white solid after purification by silica-gel column chromatography using a mixture of ethyl acetate with hexanes $(15-20 \% v / v)$ as eluent $R_{f}=0.38$ (hexanes-AcOEt, 8/2, v/v); $\mathrm{mp}=80-84{ }^{\circ} \mathrm{C}$, FT-IR $(\mathrm{ATR}) v_{\max } / \mathrm{cm}^{-1} 1697,1651(\mathrm{C}=\mathrm{O}$ amide), 2122 (N3), 3343 (NH amide); ${ }^{1} \mathrm{H}$ NMR (300 MHz, $\left.\mathrm{CDCl}_{3}, \mathrm{TMS}\right): \delta 6.94$ (d, J = 9.0 $\mathrm{Hz}, 2 \mathrm{H})), 6.78(\mathrm{~d}, J=9.0 \mathrm{~Hz}, 2 \mathrm{H}), 6.47(\mathrm{~s}, 1 \mathrm{H}), 6.92(\mathrm{~s}, 1 \mathrm{H}), 5.15(\mathrm{~d}, J=18.0,1 \mathrm{H}), 4.68-4.53$ $(\mathrm{m}, 3 \mathrm{H}), 4.20(\mathrm{~d}, \mathrm{~J}=18.0 \mathrm{~Hz}, 1 \mathrm{H}), 3.85-3.77(\mathrm{~m}, 4 \mathrm{H}), 1.42(\mathrm{t}, \mathrm{J}=6.0 \mathrm{~Hz}, 3 \mathrm{H}), 1.33(\mathrm{~s}, \mathrm{H}, 9 \mathrm{H})$; ${ }^{13} \mathrm{C} \mathrm{NMR}$ (75 MHz, CDCl $\left.3, \mathrm{TMS}\right): \delta 214.4,168.6,165.5,159.4,147.7,144.4,142.2,139.0,128.2$, $126.9,120.6,114.4,110.7,71.3,55.6,54.2,52.2,50.1,39.5,28.7,14.0$.

3.2.5. S-(2-((1-(4-Azido-2,3,5,6-tetrafluorophenyl)-2-(cyclohexylamino)-2-oxoethyl)(4methoxybenzyl)amino)-2-oxoethyl) O-ethyl carbonodithioate (10e)

The product was obtained in $92 \%$ as a white solid after purification by silica-gel column chromatography using a mixture of ethyl acetate with hexanes $(15-20 \% v / v)$ as eluent $R_{f}=0.33$ (hexanes-AcOEt, 8/2, v/v); mp = 132-136 ${ }^{\circ} \mathrm{C}$, FT-IR (ATR) vmax $/ \mathrm{cm}^{-1} 1660(\mathrm{C}=\mathrm{O}$ amide), $2123\left(\mathrm{~N}_{3}\right), 3378$ (NH amide); ${ }^{1} \mathrm{H}$ NMR (300 MHz, $\left.\mathrm{CDCl}_{3}, \mathrm{TMS}\right): \delta 6.94$ (d, J = 9.0 $\mathrm{Hz}, 2 \mathrm{H})), 6.78(\mathrm{~d}, J=9.0 \mathrm{~Hz}, 2 \mathrm{H}), 6.47(\mathrm{~s}, 1 \mathrm{H}), 6.92(\mathrm{~s}, 1 \mathrm{H}), 5.15(\mathrm{~d}, J=18.0,1 \mathrm{H}), 4.68-4.53$ $(\mathrm{m}, 3 \mathrm{H}), 4.20(\mathrm{~d}, J=18.0 \mathrm{~Hz}, 1 \mathrm{H}), 3.85-3.77(\mathrm{~m}, 4 \mathrm{H}), 1.42(\mathrm{t}, \mathrm{J}=6.0 \mathrm{~Hz}, 3 \mathrm{H}), 1.33(\mathrm{~s}, \mathrm{H}, 9 \mathrm{H})$; ${ }^{13} \mathrm{C} \mathrm{NMR}$ (75 MHz, CDCl $\left.3, \mathrm{TMS}\right):$ ' $215.1,168.7,165.5,159.3,148.3,143.0,138.2,137.9,128.0$, $126.9,120.7,114.4,110.6,71.5,55.6,53.8,50.1,49.4,39.3,33.0,25.7,25.2,14.0$.

3.2.6. S-(2-((1-(4-Azido-2,3,5,6-tetrafluorophenyl)-2-((2,6-dimethylphenyl)amino)-2-oxoethyl)(4-methoxybenzyl)amino)-2-oxoethyl) O-ethyl carbonodithioate e (10f)

The product was obtained in $55 \%$ as a white solid after purification by silica-gel column chromatography using a mixture of ethyl acetate with hexanes (15-20\% v/v) as eluent $R_{f}=0.24$ (hexanes-AcOEt, 8/2, v/v); $\mathrm{mp}=136-140{ }^{\circ} \mathrm{C}, \mathrm{FT}-\mathrm{IR}(\mathrm{ATR}) v_{\max } / \mathrm{cm}^{-1} 1672,1656$ (C=O amide), $2122\left(\mathrm{~N}_{3}\right), 3358$ (NH amide); ${ }^{1} \mathrm{H}$ NMR (300 MHz, $\left.\mathrm{CDCl}_{3}, \mathrm{TMS}\right): \delta 6.94(\mathrm{~d}, J=$ $9.0 \mathrm{~Hz}, 2 \mathrm{H})), 6.78(\mathrm{~d}, J=9.0 \mathrm{~Hz}, 2 \mathrm{H}), 6.47(\mathrm{~s}, 1 \mathrm{H}), 6.92(\mathrm{~s}, 1 \mathrm{H}), 5.15(\mathrm{~d}, J=18.0,1 \mathrm{H}), 4.68-$ $4.53(\mathrm{~m}, 3 \mathrm{H}), 4.20(\mathrm{~d}, J=18.0 \mathrm{~Hz}, 1 \mathrm{H}), 3.85-3.77(\mathrm{~m}, 4 \mathrm{H}), 1.42(\mathrm{t}, \mathrm{J}=6.0 \mathrm{~Hz}, 3 \mathrm{H}), 1.33(\mathrm{~s}, \mathrm{H}$, 9H); ${ }^{13} \mathrm{C} \mathrm{NMR}$ (75 MHz, CDCl 3 , TMS): $\delta$ 216.0, 169.0, 165.3, 159.5, 147.8, 143.3, 138.0, 136.0, $133.2,128.6,128.0,126.8,121.1,114.6,109.9,71.8,55.7,53.6,50.0,39.2,18.7,14.0$.

\section{Conclusions}

In conclusion, we have developed a one-pot strategy via the Ugi-4CR/SN2 process toward the synthesis of fluoro $\alpha$-acylamino amide-xanthates. The main contributions of this work are the design and development of an MCR-based protocol towards a synthetic platform of peptidomimetic heterocycles that contain several fluorine atoms, with the aim of improving their biological properties.

Author Contributions: R.G.-M. has made a substantial, direct, and intellectual contribution to the work and M.A.R.-G. and T.R.I.-R. contributed significantly to the design and analysis of the results. All authors discussed the whole project, wrote the publication, and approved it for publication. All authors have read and agreed to the published version of the manuscript. 
Institutional Review Board Statement: Not applicable.

Informed Consent Statement: Not applicable.

Acknowledgments: RGM is grateful for financial support from DAIP-UG (154/2019, 111/2020) and CONACYT (CB-2016-285622) projects. MR-G (707974/585367) thanks CONACYT for scholarships. All authors acknowledge the Laboratorio Nacional de Caracterización de Propiedades Fisicoquímícas y Estructura Molecular (CONACYT-México, Project: 123732) for the instrumentation time provided.

Conflicts of Interest: The authors declare no conflict of interest.

\section{References}

1. Zhu, J.; Bienaymé, H. Multicomponent Reactions; Wiley-VCH: Weinheim, Germany, 2005, doi:10.1002/3527605118.

2. Koopmanschap, G.; Ruijter, E.; Orru, R.V. Isocyanide-based multicomponent reactions towards cyclic constrained peptidomimetics. Beilstein J. Org. Chem. 2014, 10, 544-598, doi:10.3762/bjoc.10.50.

3. Purser, S.; Moore, P.R.; Swallow, S.; Gouverneur, V. Fluorine in medicinal chemistry. Chem. Soc. Rev. 2008, 37, 320-330, doi:10.1039/B610213C.

4. Quiclet-Sire, B.; Zard, S.Z. Powerful Carbon-Carbon Bond Forming Reactions Based on a Novel Radical Exchange Process Chem. Eur. J. 2006, 12, 6002-6016, doi:10.1002/chem.200600510.

5. Gámez-Montaño, R.; Ibarra-Rivera, T.; Kaïm, L.; Miranda, L. Efficient Synthesis of Azaspirodienones by Microwave-Assisted Radical Spirocyclization of Xanthate-Containing Ugi Adducts. Synthesis 2010, 8, 1285-1290, doi:10.1055/s-0029-1218700.

6. Rentería-Gómez, A.; Islas-Jácome, A.; Jiménez-Halla, J.O.C.; Gámez-Montaño, R. Regiospecific synthesis of 1-acetamide-5methoxy-2-oxindoles in two steps: (Ugi-SN2)/xanthate mediated free radical cyclization. Tetrahedron Lett. 2014, 55, 6567-6570, doi:10.1016/j.tetlet.2014.10.026.

7. Gordillo-Cruz, R.E.; Rentería-Gómez, A.; Islas-Jácome, A.; Cortes-García, C.J.; Díaz-Cervantes, E.; Robles, J.; Gámez-Montaño, R. Synthesis of 3-tetrazolylmethyl-azepino [4,5-b]indol-4-ones in two reaction steps: (Ugi-azide/N-acylation/SN2)/free radical cyclization and docking studies to a 5-Ht6 model. Org. Biomol. Chem. 2013, 11, 6470, doi:10.1039/c3ob41349g.

8. Chaturvedi, D.; Ray, S. An Efficient, One-Pot, Triton-B Catalyzed Synthesis of O-Alkyl-S-methyl Dithiocarbonates. Chem. Mon. 2006, 137, 1219-1223, doi:10.1007/s00706-006-0514-0.

9. El Kaïm, L.; Grimaud, L.; Miranda, L.D.; Vieu, E.; Cano-Herrera, M.-A.; Perez-Labrada, K. New xanthate-based radical cyclization onto alkynes. Chem. Commun. 2010, 46, 2489-2491, doi:10.1039/b924207d.

10. Kaïm, L.E.; Grimaud, L.; Miranda, L.D.; Vieu, E. Ugi/xanthate cyclizations as a radical route to lactam scaffolds. Tetrahedron Lett. 2006, 47, 8259-8261, doi:10.1016/j.tetlet.2006.09.123. 